\title{
Kendali Kecepatan Motor DC Berbasis Fuzzy Setting Point pada Labview
}

\author{
Sabar Triyani ${ }^{1^{*}}$, Sumantri K.Risandriya,ST.,MT ${ }^{1^{*}}$ \\ ${ }^{1}$ Politeknik Negeri Batam, Program Studi Teknik Mekatronika \\ Jl. Ahmad Yani, Kecamatan Batam Kota, Batam 29461, Indonesia \\ *E-mail: sabartriyani@gmail.com, sumantri_k@hotmail.com
}

\begin{abstract}
Abstrak - Kelebihan motor DC adalah mudahnya untuk dikendalikan kecepatan putarnya namun harus tetap maintenance untuk menjaga performanya. Dari kelebihan tersebut timbul suatu masalah dimana banyak yang menginginkan agar motor DC dapat berputar dengan kecepatan stabil. Oleh karena itu dibuatlah suatu alat yang mengatur kecepatan motor DC dengan menggunakan sistem logika Fuzzy dengan setting-point pada LabVIEW. Logika Fuzzy sendiri merupakan pengendali yang terbilang efektif karena memiliki respon sistem yang stabil dan tidak perlu mencari model matematisnya. Input Fuzzy dirancang dengan 2 masukan yaitu error dan delta error. Input Fuzzy akan diproses oleh NI USB 6008 dengan menggunakan program LabVIEW kemudian menghasilkan sinyal PWM sebagai pengontrol kecepatan motor. Proses Fuzzy logic menggunakan metode defuzzifikasi COA (Center Of Area) non-singleton. Pada pengendalian motor DC Fuzzy pada labVIEW dapat digunakan sebagai pengontrol motor dengan kecepatan stabil. Meskipun dengan nilai setpoint yang diubah namun kecepatan tetap terjaga kestabilannya. Berdasarkan hasil percobaan yang telah dilakukan dengan memasukan set point pada kecepatan 0-3000 dengan rentan masing-masing $250 \mathrm{rpm}$, hasil keakurasian output menghasilkan error tertinggi yaitu \pm 118.928 pada setting point $1000 \mathrm{rpm}$ dan error terendah yaitu \pm 2.9101 pada setting point $2500 \mathrm{rpm}$.
\end{abstract}

Kata kunci : Motor DC, Fuzzy, labview, sensor encoder

\section{PENDAHULUAN}

Motor DC merupakan aktuator yang sangat lazim untuk digunakan. Motor Dc sangat populer digunakan pada dunia industri, mulai dari motor conveyor, motor pembuka penutup pintu/gate dan lainnya dalam bidang produksi maupun industri. Motor DC mempunyai kelebihan salah satunya yaitu dapat mencapai nilai maksimum dan motor DC juga tidak memiliki suara yang keras (bising) ketika motor berputar. Selain itu, kelebihan motor DC lainnya merupakan mudahnya untuk dikendalikan kecepatan putarnya namun harus tetap maintenance untuk menjaga performanya. Banyak hal yang mempengaruhi kecepatan motor DC, diantaranya pada saat diberi beban maka kecepatan motor akan melambat.

Untuk mengatasi maslah tersebut maka dalam penelitian ini berbasis Fuzzy-setting point pada labVIEW sebagai pengontrolnya agar motor dapat berputar stabil meskipun diberi beban yang berbeda.

Penelitian ini memiliki batasan masalah yaitu motor yang dikendalikan adalah motor dengan tegangan $12 \mathrm{Vdc}$. Adapun tujuan dari penelitian ini yaitu mengendalikan kecepatan motor DC agar tetap terjaga kestabilannya serta mengaplikasikan fungsi Fuzzy pada LabVIEW untuk mengatur setting point-nya adapun manfaatnya adalah mengatur kecepatan motor DC agar terjaga sesuai dengan nilai setpoint, baik pada saat diberi beban ataupun tidak.

\section{DASAR TEORI}

\section{A. Motor DC}

Motor DC alat yang mengubah energi listrik DC menjadi energi mekanik putaran. Sebuah motor DC dapat difungsikan sebagai generator atau sebaliknya generator DC dapat difungsikan sebagai motor DC [1]. Bagian-bagian yang penting dari motor DC dapat ditunjukkan pada Gambar 1.

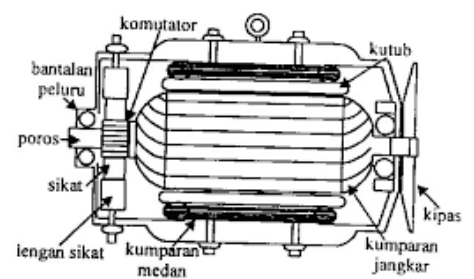

Gambar 1. Bagian-bagian Motor DC [1]

Motor DC memiliki kemampuan untuk dapat dikontrol arah beserta besar kecepatannya. Arah putaran motor diatur dengan cara membalikan polaritas tegangan sedangkan kecepatan motor diatur melalui pengaturan tegangannya. Oleh karena itu, pada penelitian ini pengaturan tegangan di petakan (mapping) dengan nilai PWM (Pulse Width Modulation) untuk mengendalikan kecepatan putar motor. PWM sendiri merupakan sinyal yang dapat memvariasikan lebar pulsanya, rentang nilai PWM berkisar dari 0-255, lebar pulsa pada PWM disebut dengan duty cycle. Prinsip kerja PWM yaitu dengan mengatur gelombang persegi sehingga dapat menjadi supply bagi motor DC dengan pulsa yang dihasilkan berupa HIGH dan LOW. Untuk menunjang penelitian ini juga dibutuhkan hardware berupa NI USB 6008 dimana tegangan maksimal yang dihasilkan adalah $5 \mathrm{~V}$. Sedangkan motor DC yang digunakan memiliki tegangan lebih dari $5 \mathrm{~V}$ sehingga dibutuhkan suatu driver motor yang memiliki konsep Hbridge.

\section{B. Fuzzy Logic}

Fuzzy logic banyak digunakan karena Fuzzy logic mirip dengan cara berpikir manusia. Fuzzy logic adalah suatu logika yang merepresentasikan cara berpikir manusia dalam bentuk matematis yang dapat mengolah ketidakpastian dan variabelvariabel linguistik. 
Logika Fuzzy melibatkan aturan-aturan yang dinyatakan dengan kata-kata yang tidak memerlukan presisi tinggi serta terdapat toleransi untuk data yang kurang tepat [3]. Struktur dasar pengendali Fuzzy diperlihatkan pada Gambar 2.

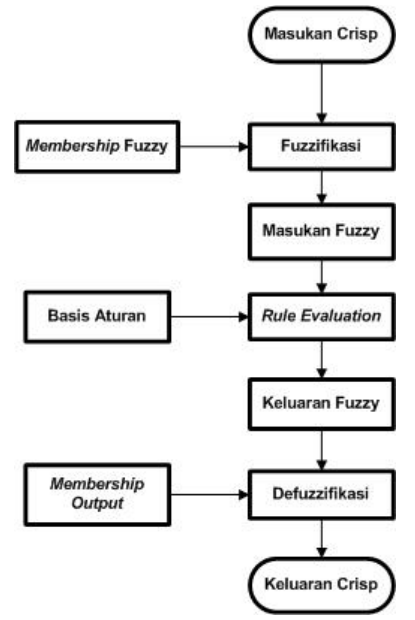

Gambar 2. Struktur Pengendali Fuzzy

Dari Gambar 2 dapat kita lihat bahwa secara garis besar ada 3 tahapan dalam logika Fuzzy yaitu fuzzifikasi, rule evaluation dan defuzzifikasi.

\section{1) Fuzzifikasi}

Fuzzifikasi merupakan sutau tahapan untuk merubah nilai input yang berupa variabel crisp menjadi bentuk Fuzzy dengan menentukan nilai derajat keanggotaan terlebih dahulu. Sehingga kemudian input dapat dikelompokkan pada himpunan Fuzzy yang tepat agar masukan controller Fuzzy bisa dipetakan agar sesuai dengan himpunan Fuzzy.

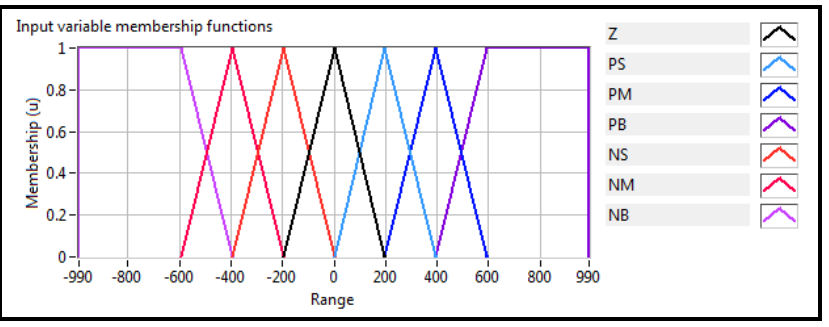

Gambar 3. Membership input Fuzzy

Keterangan :

$\mathrm{Z} \quad$ : Zero

PS : Positive Small

PM : Positive Medium

PB : Positive Big

NS : Negative Small

NM : Negative Medium

NB : Negative Big

\section{2) Rule Evaluation}

Basis aturan merupakan aturan Fuzzy yang digunakan untuk pengendalian sistem. Aturan itu sendiri dibuat berdasarkan logika manusia yang berkaitan dengan jalan pikiran serta penelitian yang dilakukan pembuatnya. Aturan ini dibuat untuk membandingkan antara masukan dari fuzzifikasi dengan aturan yang sudah dibuat sesuai intuisi. Sehingga output yang diiginkan akan sesuai dengan rule base yang telah dibuat.

\begin{tabular}{|c|c|c|c|c|c|c|c|c|}
\hline \multicolumn{9}{|c|}{ ERROR } \\
\hline \multirow{8}{*}{ 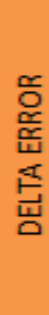 } & & PB & PM & PS & $z$ & NS & NM & NB \\
\hline & PB & PB & PB & PB & PM & PS & PS & $z$ \\
\hline & PM & PB & PB & PM & PS & PS & $z$ & NS \\
\hline & PS & PB & PM & PS & PS & $z$ & NS & NM \\
\hline & $z$ & PM & PS & PS & $z$ & NS & NS & NM \\
\hline & NS & PM & PS & $z$ & NS & NS & NM & NB \\
\hline & NM & PS & $z$ & NS & NS & NM & NB & NB \\
\hline & NB & $z$ & NS & NM & NM & NB & NB & NB \\
\hline
\end{tabular}

Gambar 4. Rule Evaluation

\section{3) Defuzzifikasi}

Defuzzifikasi merupakan proses lanjutan setelah pengambilan keputusan berdasarkan basis aturan (rule evaluation) yang sudah ditetapkan. Pada penelitian ini digunakan output non-singleton dengan metode COA (Centre of Area) sebagai keluarannya.

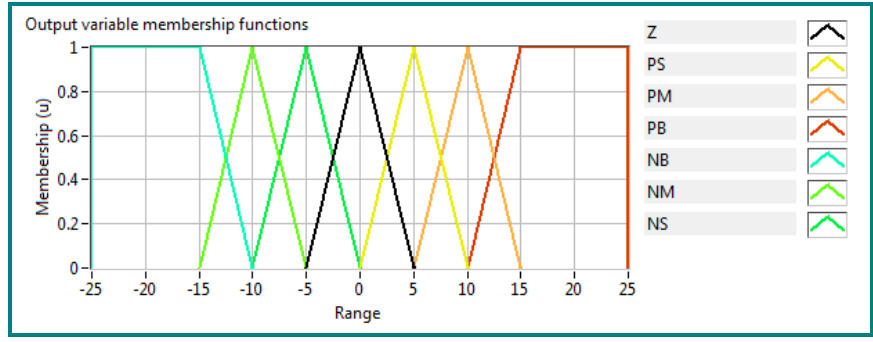

Gambar 5. Membership Output

\section{LABVIEW}

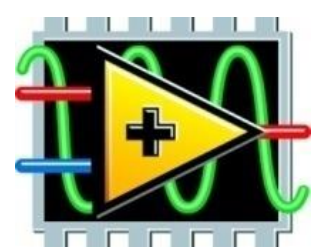

Gambar 6. Simbol Software LabVIEW

LabVIEW (Laboratory Virtual Instrumentation Engineering Workbench), adalah eprangkat lunak komputer untuk pemrosesan dan visualisasi data dalam bidang akuisisi data, kendali instrumentasi serta automasi industri yang pertama kali dikembangkan oleh perusahaan National Instruments pada tahun 1986. LabVIEW memiliki 2 jendela yang berbeda fungsinya yaitu Front Panel digunakan untuk membangun sebuah VI (Virtual Instrument), menjalankan mendebug program, sedangkan Blok diagram adalah jendela yang berisikan source code yang dibuat dan berfungsi sebagai instruksi untuk front panel.

D. NI USB 6008-6009

National Instrument USB 6008 adalah perangkat keras yang menyediakan dasar data aquisisi (DAQ) yang berfungsi 
untuk pengaplikasian data logging, pengukuran yang praktis dan untuk media pembelajaran [4].

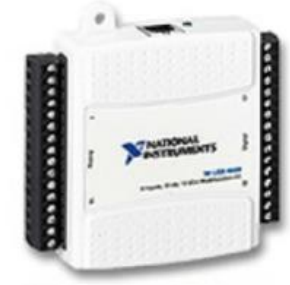

Gambar 7. NI USB 6008 [4]

\section{E. EMS 30A H-bridge}

EMS 30 A H-Bridge merupakan H-Bridge berbasis VNH3SP30 yang didesain untuk menghasilkan 2 arah dengan arus kontinyu sampai dengan $30 \mathrm{~A}$ pada tegangan 5,5 Volt sampai 36 Volt (IC VNH2SP30 hanya sampai 16 V). Modul ini dilengkapi dengan rangkaian sensor arus beban yang dapat digunakan sebagai umpan balik ke pengendali. Modul ini mampu men-drive beban-beban induktif seperti misalnya relay, solenoida, motor DC, motor stepper, dan berbagai macam beban lainnya.

Tabel 1. Alokasi Pin Interface Header J1

\begin{tabular}{|c|c|c|l|}
\hline Pin & Nama & I/O & \multicolumn{1}{|c|}{ Fungsi } \\
\hline 1 & MIN 1 & I & $\begin{array}{l}\text { Pin Input untuk menentukan } \\
\text { output MOUT1. }\end{array}$ \\
\hline 2 & MIN 2 & & $\begin{array}{l}\text { Pin input untuk menentukan } \\
\text { output MOUT2. }\end{array}$ \\
\hline 3 & MEN 1 & I/O & $\begin{array}{l}\text { Pin enable untuk output } \\
\text { MOUT1 Diberi logika High } \\
\text { untuk mengaktifkan half H- } \\
\text { Bridge 1, diberi logika Low } \\
\text { secara eksternal untuk } \\
\text { menonaktifkan half H-Bridge 1. }\end{array}$ \\
\hline 4 & MEN 2 & I/O & $\begin{array}{l}\text { Pin untuk enable output } \\
\text { MOUT2 Diberi logika High } \\
\text { untuk mengaktifkan half H- } \\
\text { Bridge 2 diberi logika Low } \\
\text { secara eksternal untuk } \\
\text { menonaktifkan half H-Bridge. }\end{array}$ \\
\hline 5 & MCS & O & $\begin{array}{l}\text { Output tegangan analog yang } \\
\text { berbanding lurus dengan arus } \\
\text { beban (Range output 0 5 V) } \\
\text { Tersedia untuk IC VNH2SP30 }\end{array}$ \\
\hline 6 & MPWM & I & $\begin{array}{l}\text { Pin input untuk mengatur kerja } \\
\text { modul H-Bridge secara PWM. }\end{array}$ \\
\hline 7,9 & VCC & - & $\begin{array}{l}\text { Terhubung ke catu daya untuk } \\
\text { input (5 Volt). }\end{array}$ \\
\hline 8,10 & PGND & - & $\begin{array}{l}\text { Titik referensi untuk catu daya } \\
\text { input. }\end{array}$ \\
\hline
\end{tabular}

\section{F. Rotary Encoder}

Rotary encoder adalah komponen yang berfungsi untuk memantau suatu gerakan putaran maupun posisi. Dari putaran itu data yang terpantau akan diubah dalam bentuk digital yang kemudian akan diubah menjadi lebar pulsa yang kemudian dihubungkan ke controller dalam penelitian ini menggunakan NI USB 6008. Dari data yang didapat kemudian akan diolah menjadi data berupa kecepatan.

Konstruksi dari rotary encoder berupa piringan tipis yang dikopel dengan bagian motor DC yang berputar. Pada piringan terdapat lubang kecil dipinggiran lingkaran yang berguna sebagai penghantar cahaya LED phototransistor. Piringan tersebut berputar sesuai dengan kecepatan putaran motor. Oleh karena itu, semakin banyak lubang yang ada pada piringan maka semakin banyak pula pulsa yang dihasilkan oleh rotary encoder pada satu kali putaran.

\section{PERANCANGAN SISTEM}

\section{A. Perancangan Perangkat Keras}

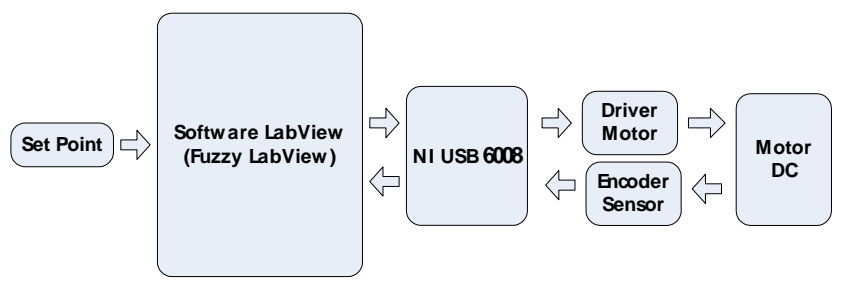

Gambar 8. Diagram blok perangkat keras

Berdasarkan dari Gambar 8 di atas digunakan beberapa perangkat keras yang berguna untuk mendukung proses kerja alat yaitu NI USB yang berguna sebagai pengolah data yang masuk dari PC yang kemudian data akan diubah dalam bentuk tegangan sehingga dapat menggerakan actuator yaitu motor DC. Apabila motor DC sudah bergerak maka kecepatnnya akan terbaca oleh sensor encoder dan hasil data kecepatan encoder tersebut akan menjadi inputan kembali bagi NI USB 6008 yang kemudian akan menjadi pembanding apakah kecepatan yang dibaca oleh sensor encoder sama dengan set point yang diberikan didalam LabVIEW. Jika data kecepatan yang dibaca sensor encoder kurang dari set point atau lebih dari set point yang diberikan, maka labview akan melooping data kembali dan dikeluarkan output dalam bentuk tegangan sehingga data kecepatan yang dihasilkan sama dengan set point yang diberikan. Sehingga dengan software labview kita dapat melihat keluaran kecepatan dari motor.

\section{B. Rancangan Perangkat Lunak (Software)}

Flowchart di bawah ini merupakan alur kerja sistem secara umum. Alur diagram menjelaskan proses kerja yang terjadi dari program start hingga masuk ke master. Selanjutnya proses yang dijalankan setiap slave untuk mengirimkan data analog dari setiap sensor. Hal tersebut tergambar dalam Flowchart proses kerja sistem pada Gambar 9. 


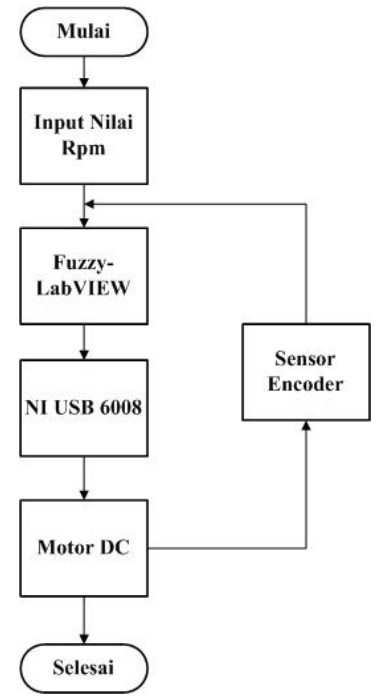

Gambar 9. Struktur pengendali Fuzzy

\section{Perancangan Mekanik}

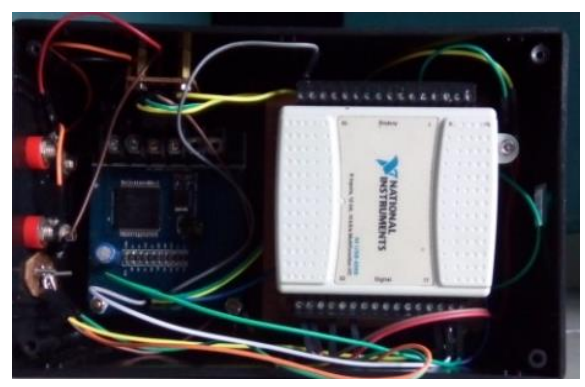

Gambar 10. Desain Mekanik

Dari Gambar 10 dapat diketahui bahwa perancangan mekanik memiliki tiga komponen utama yaitu input, NI USB 6008, motor DC, encoder sensor. Komponen input berisikan plug tegangan dari power supply. NI USB 6008 merupakan sarana komunikasi dari Labview ke motor DC dan sebaliknya. Motor DC yang digunakan adalah motor DC 12 Vdc.

\section{Instrumentasi Penelitian}

Salah satu pengujian alat ukur yang digunakan pada percobaan ini adalah menggunakan Fuzzy logic toolbox yang tersedia pada LabVIEW, tools ini menyediakan fungsi untuk menganalisa, mendesain serta mensimulasikan logika Fuzzy yang akan dirancang.

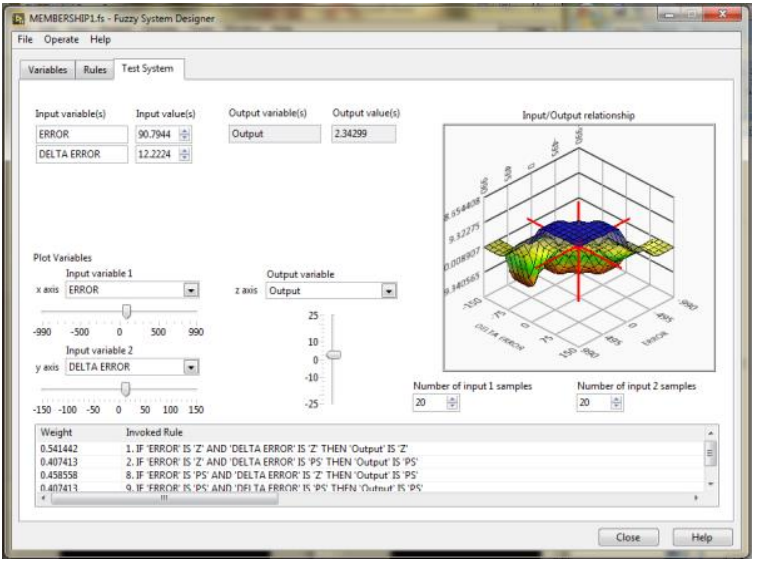

Gambar 11. Diagram alir program Master

\section{PENGUJIAN DAN ANALISA}

Berikut data pengujian kontrol kecepatan motor DC yang telah dilakukan. Dari pengujian ini kita dapat menganalisa hasil terbaik dari pengendalian kecepatan motor DC.

Untuk mengetahui respon motor DC, maka dilakukan percobaan pada kecepatan $250 \mathrm{rpm}, 2000 \mathrm{rpm}$ dan $2500 \mathrm{rpm}$. Respon dari masing-masing percobaan dapat diamati dari monitoring pada program LabVIEW yang dapat dilihat pada gambar di bawah ini.

\section{A. Pengujian Motor DC dengan Kecepatan 250 Rpm}

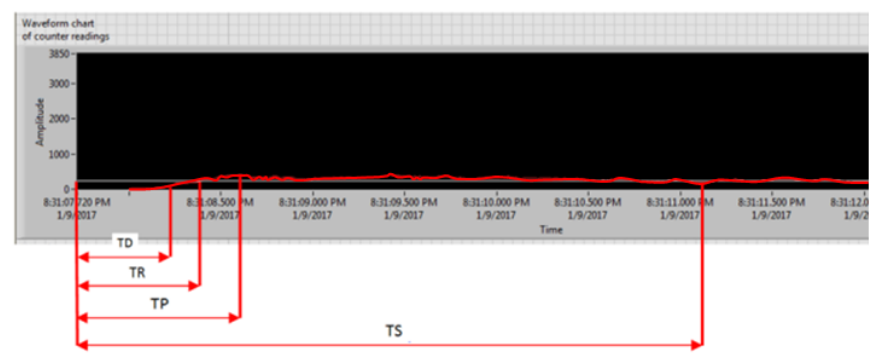

Gambar 12. Respon motor dengan sistem kendali Fuzzysetting point dengan kecepatan $250 \mathrm{rpm}$

\section{B. Pengujian Motor DC dengan Kecepatan 2000 Rpm}

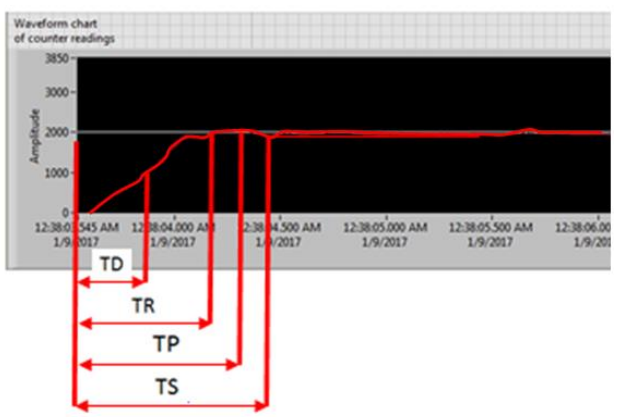

Gambar 13. Respon motor dengan sistem kendali Fuzzysetting point dengan kecepatan $2000 \mathrm{rpm}$

\section{Pengujian Motor DC dengan Kecepatan 2500 Rpm}




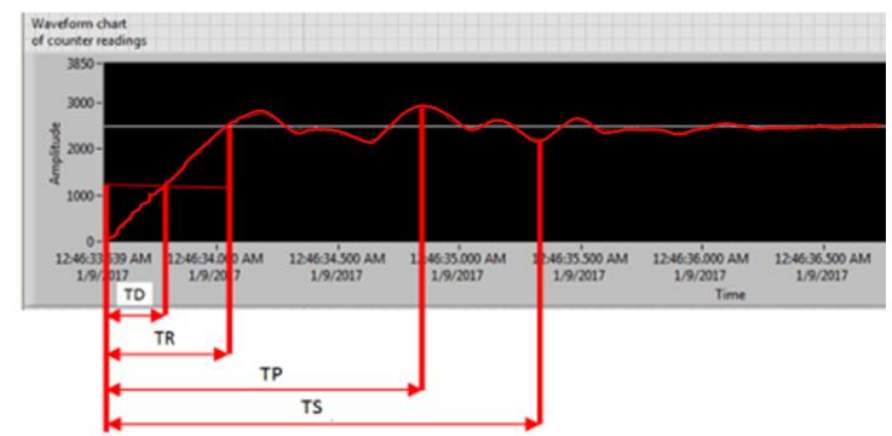

Gambar 14. Respon motor dengan sistem kendali Fuzzysetting point dengan kecepatan $2500 \mathrm{rpm}$

Dari data pengujian yang telah dilakukan dapat kita amati hasil respons motor terhadap referensi setting point. Data parameter dapat dilihat pada tabel berikut.

Tabel 2. Parameter Output Motor terhadap Fuzzy-setting point

\begin{tabular}{|c|c|c|c|c|}
\hline \multirow{2}{*}{$\begin{array}{c}\text { Referensi } \\
(\mathrm{rpm})\end{array}$} & \multicolumn{4}{|c|}{ Parameter } \\
\cline { 2 - 5 } & TD & TR & TP & TS \\
\hline 250 & 0.5465 & 0.655 & 0.905 & 0.955 \\
\hline 2000 & 0.211 & 0.521 & 1.311 & 1.861 \\
\hline 2500 & 0.53 & 0.63 & 0.79 & 3.38 \\
\hline
\end{tabular}

Keterangan :

a. Delay Time ( Td) : Waktu yang dibutuhkan oleh output untuk mencapai $50 \%$ dari kondisi setpoint.

b. Rise Time (Tr) : Waktu yang dibutuhkan oleh output dari motor dinyalakan hingga kecepatan mencapai setpoint.

c. Peak Time (Tp) : Waktu yang dibutuhkan output pertama kali untuk mencapai nilai maksimum.

d. Settling Time (Ts) : Waktu yang dibutuhkan oleh output untuk mencapai nilai setpoint dengan toleransi yang diberikan.

\section{Analisa}

Untuk menguji apakah sistem kontrol Fuzzy yang dibangun sudah benar perlu dibuktikan dengan menggunakan persamaan Fuzzy yang sudah diterapkan pada sistem. Berikut ini adalah pembuktian jika masukan sensor memberikan nilai input error dan delta error.

1) Menghitung nilai $\mu$ fungsi keanggotaan input error \& d_error

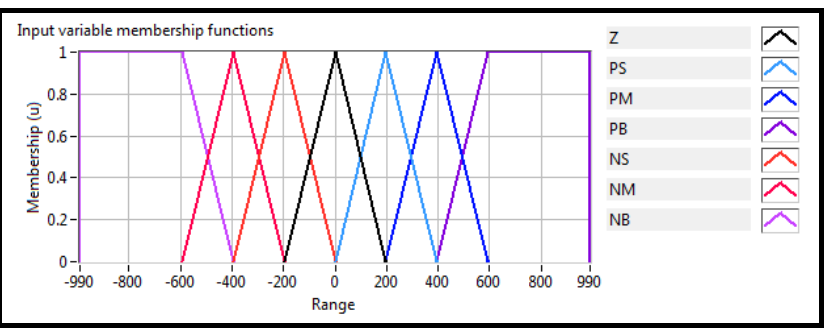

Gambar 15. Fungsi Keanggotaan input error

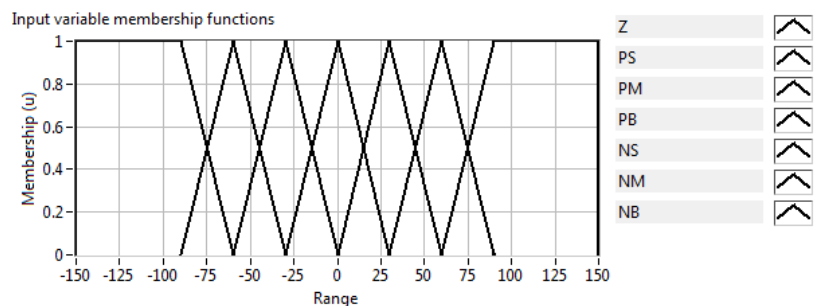

Gambar 16. Fungsi Keanggotaan input d_error

- $\quad \mu$ membership dari error 90.7944

$$
\begin{gathered}
\mu \mathrm{PB}=0 \\
\mu \mathrm{PM}=0
\end{gathered}
$$

$\mu \mathrm{PS}=\frac{(x-a)}{(b-a)}=\frac{90.7944-0}{200-0}=\frac{90.7944}{200}=0.453972$

$\mu \mathrm{Z}=\frac{(b-x)}{(b-a)}=\frac{200-90.7944}{200-0}=\frac{109.2056}{200}=0.546028$

$\mu \mathrm{NS}=0$

$\mu \mathrm{NM}=0$

$\mu \mathrm{NB}=0$

- $\mu$ membership dari d_error 12.2224

$$
\begin{aligned}
\mu \mathrm{PB} & =0 \\
\mu \mathrm{PM} & =0 \\
\mu \mathrm{PS}=\frac{(x-a)}{(b-a)}=\frac{12.2224-0}{25-0} & =\frac{12.2224}{25}=0.488896 \\
\mu \mathrm{Z}=\frac{(b-x)}{(b-a)}=\frac{25-12.2224}{25-0} & =\frac{12.7776}{25}=0.511104 \\
\mu \mathrm{NS} & =0 \\
\mu \mathrm{NM} & =0 \\
\mu \mathrm{NB} & =0
\end{aligned}
$$

\begin{tabular}{|c|c|c|c|c|c|c|c|c|}
\hline \multicolumn{9}{|c|}{ ERROR } \\
\hline \multirow{8}{*}{ 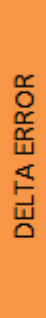 } & 1 & PB & PM & PS & Z & NS & NM & NB \\
\hline & PB & 0 & 0 & 0 & 0 & 0 & 0 & 0 \\
\hline & PM & 0 & 0 & 0 & 0 & 0 & 0 & 0 \\
\hline & PS & 0 & 0 & 0.453972 & 0.488896 & 0 & 0 & 0 \\
\hline & Z & 0 & 0 & 0.453972 & 0.511104 & 0 & 0 & 0 \\
\hline & NS & 0 & 0 & 0 & 0 & 0 & 0 & 0 \\
\hline & NM & 0 & 0 & 0 & 0 & 0 & 0 & 0 \\
\hline & NB & 0 & 0 & 0 & 0 & 0 & 0 & 0 \\
\hline
\end{tabular}

2) Perbandingan dengan Rule Evaluation

Tabel 3. Minimum Nilai $\mu$ Array

3) Menghitung Luas Trapesium berdasarkan Rule Evaluation

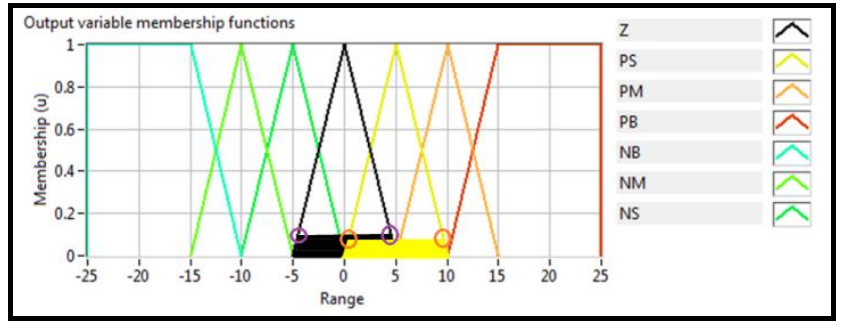

Gambar 17. Fungsi Keanggotaan Fuzzy non-singleton

○ Menghitung luas bangun untuk output PS

$$
a=\mu[x][y] \times(P S[1]-P S[0])+P S[0]
$$




$$
\begin{gathered}
a=0.453972 \times(5-0)+0=2.26986 \\
b=P S[2]-(\mu[x][y] *(P S[2]-P S[1])) \\
b=10-(0.453972 *(10-5))=7.73014 \\
\text { LPs.a }=((P S[2]-P S[0])+(b-a)) * \mu[x][y] * \frac{P S[1]}{2} \\
\text { LPS. } b=((P S[2]-P S[0])+(b-a)) *(\mu[x][y] / 2) \\
\text { LPS. } a=((10-0)+((7.73014-2.26986))) * \\
\left(0.453972 \times \frac{5}{2}\right)=17.5463355804 \\
\text { LPS. } b=((10-0)+((7.73014-2.26986))) * \\
\left(\frac{0.459972}{2}\right)=3.509256711608
\end{gathered}
$$

○ Menghitung luas bangun untuk output Z

$$
\begin{gathered}
a=\mu[x][y] \times(Z[1]-Z[0])+Z[0] \\
a=0.511104 \times(0-(-5))+(-5)=0.511104 \\
b=Z[2]-(\mu[x][y] * Z[2]-Z[1] \\
b=5-(0.511104 *(5-0)=2.44448
\end{gathered}
$$$$
L Z . a=((Z[2]-Z[0])+(b-a)) * \mu[x][y] * \frac{Z\lfloor 1]}{2}
$$$$
L Z . b=((Z[2]-Z[0])+(b-a)) *(\mu[x][y] / 2)
$$$$
L Z . a=((5-(-5))+((2.44448-0.511104))) *
$$$$
\left(0.511104 \times \frac{0}{2}\right)=0
$$$$
L Z . a=((5-(-5))+((2.44448-0.511104))) *
$$$$
\left(\frac{0.511104}{2}\right)=3.049598103552
$$

4) Menghitung defuzifikasi dengan metode centroid serta menghitung error dengan membandingkan dengan tools Fuzzy labview

$$
\begin{gathered}
\text { defuzifikasi }=\frac{\int \mu c(z) x z d z}{\mu c(z) d z} \\
\text { defuzifikasi }=L P S a+L Z a / L P S b+L Z b
\end{gathered}
$$

defuzifikasi $=\frac{17.5463355807+0}{3.50926711608+3.049598103552}=2.675209048$

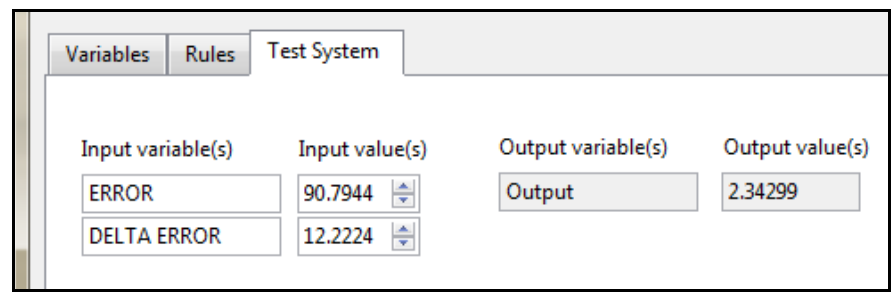

Gambar 18. Hasil Output non-singleton pada toolkit LabVIEW

\section{KESIMPULAN}

Berdasarkan hasil dan analisa dan pembahasan maka dapat disimpulkan sebagai berikut:

1. Perancangan alat dengan menggunakan metode Fuzzysetting point pada labview dapat mengontrol kecepatan motor DC dengan nilai setting point yang berubah-ubah.

2. Komunikasi Fuzzy dengan LabVIEW dapat dilakukan dengan memanfaatkan toolkit Fuzzy yang sudah tersedia di labVIEW yang kemudian diproses oleh NI USB 6008.

3. Berdasarkan hasil percobaan yang telah dilakukan dengan memasukan set point pada kecepatan 0-3000 rpm dengan rentan masing-masing $250 \mathrm{rpm}$, hasil keakurasian output menghasilkan error tertinggi yaitu \pm 118.928 pada setting point $1000 \mathrm{rpm}$ dan error terendah yaitu \pm 2.9101 pada setting point $2500 \mathrm{rpm}$.

\section{DAFTAR PUSTAKA}

[1] "Motor DC". Internet :https://www.academia.edu/ 9091244/MAKALAH_MOTOR_DC, [23 Mei 2016] .

[2] "Karakteristik Motor DC". Internet : http://dok umen.tips/documents/karakteristik-motor-dc.html, [17 Mei 2016].

[3] Sumantri K.R, ST.MT., Modul Praktikum, Topik: "Logika Fuzzy." Politeknik Negeri Batam, Batam, 2015.

[4] Zulhendri Agus dkk, " Rancang Bangun Sistem Monitoring dan Pengendalian Level Cairan dengan LabVIEW Berbasis Mikrokontroler Mbed NXP LPC1768 ", JITET - Jurnal Informatika dan Teknik Elektro Terapan,vol 1, pp.8, Januari 2012.

"Tampilan LabVIEW “. Internet :http://elib. unikom.ac.id/files/disk1/398/jbptuni kompp-gdlsetiawanar-19859-9-babii.pdf, [17 Mei 2016]

[6] "NI USB 6008". Internet : http://sine.ni.com/nips/ cds/view/p/lang/en/nid/201986, [16 Mei 2016]. 